\title{
BMJ Open Alcohol consumption among university students: a typology of consumption to aid the tailoring of effective public health policy
}

\author{
Martin P Davoren, ${ }^{1}$ Mary Cronin, ${ }^{1}$ Ivan J Perry, ${ }^{1}$ Karl O'Connor ${ }^{2}$
}

To cite: Davoren MP, Cronin M, Perry IJ, et al. Alcohol consumption among university students: a typology of consumption to aid the tailoring of effective public health policy. BMJ Open 2016;6:e011815. doi:10.1136/bmjopen-2016011815

- Prepublication history for this paper is available online. To view these files please visit the journal online (http://dx.doi.org/10.1136/ bmjopen-2016-011815).

Received 8 March 2016 Revised 27 July 2016 Accepted 2 September 2016

CrossMark

\footnotetext{
${ }^{1}$ Department of Epidemiology and Public Health, University College Cork, Cork, Ireland ${ }^{2}$ School of Criminology, Politics and Social Policy, University of Ulster, Antrim, UK
}

Correspondence to Dr Martin P Davoren; m.davoren@ucc.ie

\section{ABSTRACT}

Objective: Elevated levels of alcohol consumption among university students are well documented. Policymakers have attempted to combat this issue at a university, national and international level. Tailoring public health policy to effectively tackle alcohol use is crucial. Using Q-methodology, the current study aims to develop a typology of alcohol consumption in the Irish university student population.

Setting: A large Irish university.

Participants: Hundreds of possible statements on types of consumption were generated from a systematic review and a set of one-on-one interviews. These were reduced to 36 statements, 6 statements which define each of the 6 previously defined consumption types. Participants were advised to scan through the 36 statements and fill the statements into a 'forced choice, standardised distribution'. Following this, a 45-90 min interview was conducted with students to illuminate subjectivity surrounding alcohol consumption. Analysis was conducted using $P Q$ Method and NVivo software. Principal component analysis, followed by varimax rotation, was conducted to uncover the final factor information.

Results: In total, 43 students completed the Q-study: 19 men and 24 women. A typology describing 4 distinct groupings of alcohol consumer was uncovered: the guarded drinker, the calculated hedonist, the peerinfluenced drinker and the inevitable binger. Factor loadings of each of the consumer groupings were noted for type description.

Conclusions: This is the first study to propose ideal types of alcohol consumption among a university student population. Further research is required to investigate the degree to which each of these ideal types is subscribed. However, this typology, in addition to informing public policy and strategies, will be a valuable analytic tool in future research.

\section{INTRODUCTION}

University students report exciting, invigorating and empowering experiences throughout their university lives, but these are coupled with stressful periods due to academic

\section{Strengths and limitations of this study}

- Q-methodology is a quali-quantilogical approach which combines quantitative and qualitative methods, thus providing a robust tool for investigating human subjectivity.

- This study uses both previous literature and one-on-one interviews to ensure completeness of communication on the topic for this study.

- In comparison to a recently published quantitative study investigating the prevalence of alcohol consumption among university students, Alcohol Use Disorders Identification Test (AUDIT) scores were lower in this Q-methodology study. This may be due to students reporting socially desirable responses when faced with a researcher during a one-on-one interview.

- This study provides detail on the range of shared perspectives held by students about their alcohol consumption. Future research is required to investigate the degree to which each of these ideal types is subscribed.

workload, pressure to succeed and competition among peers. ${ }^{1}$ Throughout recent decades, university authorities have expressed concerns over increasing levels of high-risk drinking. ${ }^{2-6}$ In particular, "university students are at risk for substance abuse behaviours because of changes in lifestyle, reduced parental support and stress'. Alcohol use remains the number one substance abuse problem throughout university life. ${ }^{7}$

While university authorities and public policymakers have attempted to tackle elevated levels of consumption, research signals a rise in alcohol use among students in the past decade. ${ }^{6}{ }^{7}$ Screening tools tend to categorise individuals based on consumption profile alone. Thus, measures to tackle the excessive consumption and harms associated with alcohol overlook the heterogeneous nature of consumption among the student population. $^{8-11}$ 
Tailoring effective public health policy is crucial to tackling this burgeoning issue. Recently, typologies have been hypothesised as a pertinent public health tool. ${ }^{12}$ Typologies segment their audience according to their similarities. The advantage of a typology approach is that it enhances our understanding of a societal phenomenon while making it possible to note patterns. Recently, a number of articles focusing on types of alcohol consumption have been published. ${ }^{13-15}$ A systematic review of typology papers identified six distinct types: abstainers, light drinkers, social drinkers, hedonistic drinkers, heavy alcohol consumers and problem alcohol users. ${ }^{16}$ However, this review noted that previous research employed predominantly quantitative methods. Thus, this paper aims to expand on this knowledge by providing detail on student subjectivity surrounding their consumption profile.

This study aims to develop a descriptive typology of alcohol consumption among university students with a view to enhancing more effective public health policy and strategies in this area. This involved employing Q-methodology to identify and understand the range of shared perspectives held by university students regarding the types of alcohol consumption in their lived environment.

\section{METHODS}

\section{Q-methodology}

Q-methodology provides the researcher with the structure to explore human subjectivity in a systematic and rigorous manner. ${ }^{17}$ Recently, Katz ${ }^{18}$ advised that public health part the veil of statistical anonymity and realise that there is no public health, 'just you, me and everyone else'. Q-methodology identifies the range of viewpoints held by individuals and highlights their commonly shared opinions. ${ }^{19}$ This is achieved by asking the participant to rank statements from what they believe most describes them to what least describes them. This process of consideration leads to clarity of decision-making. ${ }^{20}$ In undertaking a Q-methodology study, it is important to consider the individuals of interest, the topic under investigation and the manner in which we communicate about this topic.

\section{Concourse}

The first step in undertaking a Q-methodology study is to define the concourse. The concourse can be defined as the language used by individuals and groups as they discuss a particular topic in their everyday life. ${ }^{21}{ }^{22} \mathrm{In}$ the current research, this is the everyday language employed by students when discussing alcohol. The concourse for this study was generated through two methods: undertaking both a small-scale qualitative study and a narrative synthesis of previously published literature. ${ }^{16}$

\section{Q-statements}

Q-statements were generated from the hundreds of possible statements in the interviews and narrative synthesis.
Initially, all possible statements were divided into the six theoretically defined groups previously outlined in the narrative synthesis. ${ }^{16}$ These theoretically defined groups were: abstainers, light drinkers, social drinkers, hedonistic drinkers, heavy alcohol consumers and problem alcohol users. Statements were reviewed for similarities and differences. Just six statements for each of the six theoretically defined types were chosen to illustrate the range of perspectives which define each group. ${ }^{1623}$ The expressions of the participant or article were used, editing only the grammar of the statement. All facets of this process were discussed among co-authors. These statements and their corresponding theoretical type can be seen in table 1 .

\section{Participants}

Q-methodology maps a range of viewpoints, not the extent to which those viewpoints are subscribed. Thus, it is not subjected to sample size calculations. ${ }^{24}$ Samples in Q-methodology studies need to be carefully selected rather than randomised so that variability in a specific case or situation can be analysed. Therefore, a purposive sample of university students, from an Irish university, registered to clubs, societies and those not registered to either were sampled. University students in this study are defined as young adults, aged 18-24 years, who have recently completed their second-level education and are currently in pursuit of their undergraduate degree. The club and society chosen were distinctly different; by reputation, one would be considered conservative and the other liberal. The author (MPD) asked that a note be circulated to members of the chosen society or club. This note detailed the aims and objectives of the study in addition to outlining the procedure involved when participating in the research and the amount of time it would take to participate. Interested individuals were asked to contact the lead author (MPD). Non-club or society students were recruited in areas and buildings where students regularly frequent. These included restaurants, the library, coffee shops and social spaces. A similar note was circulated and interested parties were asked to email their interest.

\section{Procedure}

One researcher (MPD) conducted all interviews at a time, date and location suitable to the student. Interviews were undertaken in March and April 2014. Students signed a consent form and were rebriefed on the aims and objectives of the research and advised on the confidential and voluntary nature of the project. Students were then advised to read through the 36 statements which were displayed on cards (table 1). Firstly, participants sorted these 36 cards into three groups: agree, disagree and neither agree nor disagree. Secondly, they were asked to fill the cards into the 'Q-sort' which was along a continuum from 'least describes me' to 'most describes me' (figure 1). Thirdly, students were given a short questionnaire to complete 
Table 1 List of statements used in this Q-study

\begin{tabular}{|c|c|c|}
\hline 1 & When I go out, the aim of my night is to become drunk. & Heavy \\
\hline 2 & I only drink small amounts of alcohol. & Light \\
\hline 3 & Alcohol is part of my social life. & Social \\
\hline 4 & I abstain from alcohol on nights out. & Abstainer \\
\hline 5 & A good night out involves drinking enough to be happy. & Hedonistic \\
\hline 6 & In my experience when you drink, you tend to forget parts of the night. & Heavy \\
\hline 7 & I get myself into dangerous situations following alcohol consumption. & Harmful/problem \\
\hline 8 & It's normal to try and hide the amount of alcohol I consume from people. & Harmful/problem \\
\hline 9 & I drink to be more outgoing. & Social \\
\hline 10 & I'm quite health conscious and this leads me to abstain from alcohol. & Abstainer \\
\hline 11 & When I consume alcohol, it occurs in a group. & Social \\
\hline 12 & I think drinking helps me to feel part of my group. & Social \\
\hline 13 & I abstain from alcohol as I like to remain in control. & Abstainer \\
\hline 14 & I expect no problems from my alcohol consumption. & Light \\
\hline 15 & When I think of drinking, the first thing that comes to mind is fun. & Hedonistic \\
\hline 16 & Alcohol helps me escape my problems. & Harmful/problem \\
\hline 17 & I believe that night outs and drinking too much go together. & Heavy \\
\hline 18 & Alcohol facilitates having fun. & Hedonistic \\
\hline 19 & I feel that l'm failing to reach my potential due to my alcohol consumption. & Harmful/problem \\
\hline 20 & I use alcohol to drown my sorrows. & Harmful/problem \\
\hline 21 & I have fun without consuming alcohol. & Abstainer \\
\hline 22 & If I were to get drunk, I would be embarrassed. & Light \\
\hline 23 & I drink alcohol infrequently. & Light \\
\hline 24 & I do not remember what happens on a night out. & Heavy \\
\hline 25 & It's better to go out drinking than to miss a good night out. & Hedonistic \\
\hline 26 & I abstain from alcohol to avoid dangerous situations. & Abstainer \\
\hline 27 & I drink to feel pleasure. & Hedonistic \\
\hline 28 & I drink to enjoy myself. & Hedonistic \\
\hline 29 & I have made a conscious decision to be a light drinker. & Light \\
\hline 30 & Socialising often involves talking and drinking with all my friends. & Social \\
\hline 31 & Drinking alone before parties in case you don't have enough to drink is a common occurrence. & Harmful/problem \\
\hline 32 & Socialising regularly involves inviting friends to my house for a party. & Social \\
\hline 33 & I keep on drinking until the alcohol is gone. & Heavy \\
\hline 34 & I made the conscious decision not to consume alcohol from an early age. & Abstainer \\
\hline 35 & I drink heavily in all social contexts. & Heavy \\
\hline 36 & I would drink 1-2 drinks during a night out. & Light \\
\hline
\end{tabular}

detailing demographic and alcohol consumption information. Hazardous alcohol consumption was estimated using the Alcohol Use Disorders Identification Test (AUDIT) developed by the WHO. ${ }^{25}$ This instrument has demonstrated high sensitivity and specificity among a population of young adults. ${ }^{14} 2627$ Hazardous alcohol consumption was defined as an AUDIT score of 8 or more. Finally, having completed the questionnaire, students participated in a one-on-one interview which lasted between 45 and $90 \mathrm{~min}$, where they described their statement distribution along the Q-sort.

\section{Analysis}

The basic distinctiveness of Q-methodology is that, unlike standard survey analysis, it is interested in establishing patterns within and across individuals rather than patterns across individual traits, such as gender, age, class, etc. As Stainton-Rogers notes, "it is not, the "constructors'-the participants-who are the focus of the approach but the 'constructions' [types] themselves". ${ }^{28} 29$ Analysis was conducted using $P Q$ Method software specifically devised for analysing Q-studies (Schmolck P. PQMethod Software. Secondary PQMethod Software. 2015. http://schmolck.userweb.mwn.de/ qmethod/). Principal component analysis followed by varimax rotation was conducted to uncover the final factor information. Factors were selected in accordance to guidelines by Webler et $a l^{30}$ This guidance noted the importance of simplicity, clarity, distinctiveness and stability of factors. ${ }^{30}$

Investigating the constructions outlined by students during one-on-one interviews was aided by an inductive approach to content analysis. This is 'a systematic and objective means of describing and quantifying phenomena' ${ }^{31}$ which complemented the factor analysis proposed by Q-methodology. Interviews were transcribed and analysed using NVivo. Initial data and concepts were then reanalysed using relational content analysis as it allows the author to identify what other words or phrases were associated with each concept and quantify these together to create the range of perspectives outlined below. 
Figure 1 Sorting template for the 36-statement Q-sort.

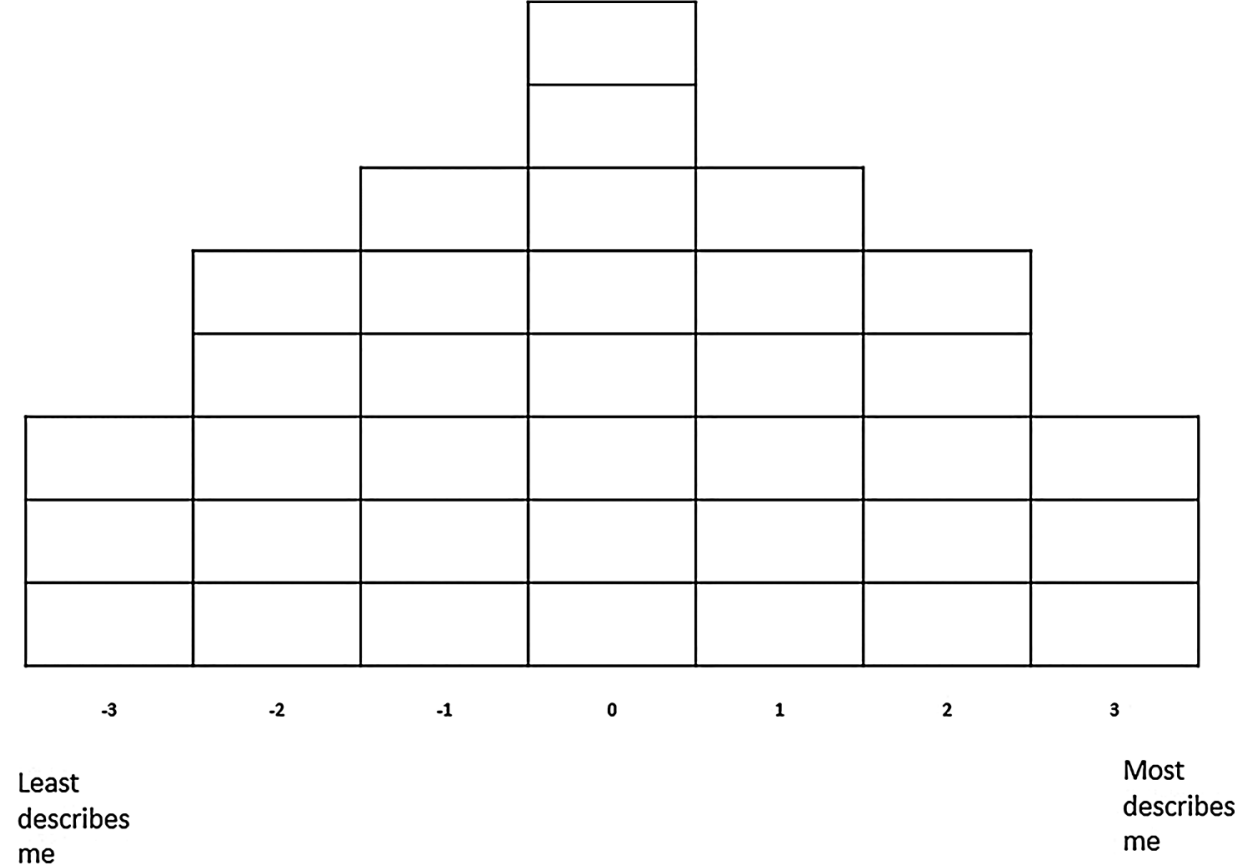

\section{RESULTS}

In total, 43 students completed the Q-sort: 11 university club members, 12 university society members and 20 non-club or society members. This Q-study identified four distinct groupings of alcohol consumer termed as 'the guarded drinker' (factor 1), 'the calculated hedonist' (factor 2), 'the peer-influenced drinker' (factor 3) and 'the inevitable binger' (factor 4). Factors 1, 3 and 4 have very few similarities and are not correlated. Factor 2 is slightly correlated with factor 3 ; however, a clear distinction was evidenced. Factor loadings were noted for the description of each type below.

Factor 1: 'guarded drinker, careful spender, controlled enjoyment': follow the rules or fear breaking them?

Factor 1 is characterised by 'cautious, controlled enjoyment'. These drinkers enjoy socialising but only within the remit of social, family or cultural rules which are selfregulated. This is the largest factor $(n=18)$. However, even in a group whose members describe their alcohol consumption as cautious and light, almost $40 \%$ have an AUDIT score signifying risky drinking. Individuals in this group reported having made a conscious decision to be a light drinker. They emphasise that the idea or memory of getting drunk ignites feelings of embarrassment within them. Factor scores describing this group can be seen in table 2 .

The rationale for making the conscious decision to be a light drinker was related to physical size, for example, "I'm small so I'm not great at putting away massive amounts of drink" or supported by being able to have fun without alcohol "sometimes I decide not to drink and sit back and laugh at the people who are getting drunk because it's funny to sit back sometimes" (participant 9).
Each time a group member outlined their reasons for being and remaining a light drinker, it was supplemented by the idea of fear, embarrassment or money. This fear was defined by many students as a feeling of embarrassment. The notion of being drunk around their friends made individuals in this group noticeably uncomfortable, even when relaying an example.

Students in this group did not drink to become drunk or until all the alcohol was gone. Furthermore, they did not feel drinking got them into dangerous situations, made them forget parts of the night or believe that alcohol facilitates them having fun. These individuals are characterised by guarded drinking, careful spending and controlled enjoyment. They tend to follow the rules or fear breaking them.

Factor 2: calculated hedonists: maximise the fun, disregard the negative

Individuals in factor $2(\mathrm{n}=13)$ described a hedonistic style of drinking. They drank alcohol to feel pleasure, to enjoy themselves, to have fun and to become drunk. This group focused on the night as a centrepiece for all social activities remarking that the first thing that comes to mind is fun. However, this was benchmarked against a fear of missing out. The majority of students in this group $(53.8 \%)$ can be described as risky or hazardous drinkers. In total, $15.4 \%$ were high-risk or harmful drinkers while a further $15.4 \%$ can be described as high risk and possibly dependent. Factor scores describing this group can be seen in table 3 .

Alcohol plays a central role in the social life of hedonists, as students use alcohol to maximise their hedonistic attitude. As students in this factor considered alcohol and their consumption, they recalled happy, carefree moments in their past where they went "out and [had] a 
Table 2 Factor 1: 'guarded drinker, careful spender, controlled enjoyment': follow the rules or fear breaking them?

\begin{tabular}{lcc}
\hline Statement & Q-sort value & Z-score \\
\hline I have fun without consuming alcohol. & 3 & 1.90 \\
When I consume alcohol, it occurs in a group. & 3 & 1.39 \\
I drink alcohol infrequently. & 2 & $1.20^{*}$ \\
I expect no problems from my alcohol consumption. & 2 & $1.20^{*}$ \\
I would drink 1-2 drinks during a night out. & 2 & $1.00^{*}$ \\
I have made a conscious decision to be a light drinker. & 2 & $0.95^{*}$ \\
I only drink small amounts of alcohol. & 1 & $0.93^{*}$ \\
I made the conscious decision not to consume alcohol. & 1 & 0.72 \\
If I were to get drunk, I would be embarrassed. & 1 & $0.41^{*}$ \\
I abstain from alcohol as I like to remain in control. & 0 & 0.33 \\
I abstain from alcohol to avoid dangerous situations. & 0 & 0.15 \\
I abstain from alcohol on nights out. & 0 & $0.08^{*}$ \\
Alcohol facilitates having fun. & 0 & -0.17 \\
When you drink, you tend to forget parts of the night. & 0 & $-0.24^{*}$ \\
Nights out and drinking too much go together. & 0 & $-0.26^{*}$ \\
It's better to go out drinking than to miss a good night out. & -1 & -0.56 \\
I keep on drinking until the alcohol is gone. & -1 & $-0.82^{*}$ \\
When I go out, the aim of my night is to become drunk. & -2 & $-1.33^{*}$ \\
I get myself into dangerous situations following alcohol. & -2 & $-1.38^{*}$ \\
Regularly, I do not remember what happens on a night out. & -2 & $-1.42^{*}$ \\
I use alcohol to drown my sorrows. & -3 & -1.76 \\
\hline *Distinguishing statement significant at <0.05. & &
\end{tabular}

Table 3 Factor 2-'you go out to drink, you drink to go out'-calculated hedonists: maximise the fun, disregard the negative

\begin{tabular}{lcc}
\hline Statement & Q-sort value & Z-scores \\
\hline I regularly drink to enjoy myself. & 3 & $1.66^{*}$ \\
I have fun without consuming alcohol. & 2 & 1.48 \\
The first thing that comes to mind is fun. & 2 & 1.33 \\
It's better to go out drinking than to miss a good night out. & 1 & 0.84 \\
I drink to be more outgoing. & 0 & 0.10 \\
Socialising involves inviting friends to a party. & 0 & -0.06 \\
I'm quite health conscious and this leads me to abstain. & 0 & $-0.34^{*}$ \\
I get myself into dangerous situations following alcohol. & -1 & -0.89 \\
I made the conscious decision not to consume alcohol. & -2 & -0.95 \\
\hline
\end{tabular}

laugh. That's pretty much it, when we go out we have good craic..." [participant 45]. However, this was noted in conjunction with the dread of missing a social occasion which forces them to go out rather than stay at home:

I would be perfectly content at home on a Tuesday or Thursday night or a Friday even I'd (think) like 'ah, just going to stay in and watch some TV'. And then one of my friends would be like 'oh are you drinking tonight' and I'd be like 'no, what's going on' 'oh, this is going on' and you're like...then you end up going out. (Participant 37)

Students in this group made no comment on the impact of alcohol on their health affecting their consumption. This differs from the 'cautious, light drinkers' in factor 1 but is similar to 'peer-influenced' drinkers in factor 3. Furthermore, they did not believe that they got themselves into dangerous situations following alcohol consumption. This was also the case for "peerinfluenced' drinkers but at odds with 'inevitable bingers' who noted this characteristic as part of their drinking pattern.

Factor 3: peer influenced with an ulterior motive: peer coercion versus personal gain

Students in factor $3(n=5)$ can be characterised as peerinfluenced consumers. All individuals in this group reported harmful or hazardous AUDIT scores. They loaded onto statements focused on consuming alcohol as part of a group or at a party (table 4). One participant highlighted that this happens "all the time. It's a group thing. I wouldn't go drinking by myself" (participant 11). This was common among students who 
Table 4 Factor 3-peer influenced with an ulterior motive: peer coercion versus personal gain

\begin{tabular}{lcc}
\hline Statement & Q-sort value & Z-score \\
\hline I drink to be more outgoing. & 3 & $1.67^{*}$ \\
I think drinking helps me to feel part of my group. & 3 & $1.56^{*}$ \\
Nights out and drinking too much go together. & 2 & 1.36 \\
I would drink 1-2 drinks during a night out. & 1 & $0.26^{*}$ \\
Alcohol helps me escape my problems. & 0 & $0.26^{*}$ \\
I use alcohol to drown my sorrows. & 0 & $-0.07^{*}$ \\
I get myself into dangerous situations following alcohol. & 0 & -0.25 \\
I feel that I'm failing to reach my potential due to alcohol. & 0 & $-0.27^{*}$ \\
I have fun without consuming alcohol. & -1 & $-0.35^{*}$ \\
I regularly drink to enjoy myself. & -1 & -0.39 \\
I drink alcohol infrequently. & -1 & -0.80 \\
I'm quite health conscious and this leads me to abstain. & -2 & $-1.08^{*}$ \\
If I were to get drunk, I would be embarrassed. & -3 & -1.46 \\
\hline${ }^{*}$ Distinguishing statement significant at $<0.05$. & &
\end{tabular}

focused on how drinking may manifest at a social occasion:

You'd be more likely to [drink]...You might have one or two when you go out with them and you're in the group and everyone just seems to be laughing, having a good time so you go with them thinking 'sure I'll go with them, it might be a bit of craic'. (Participant 25)

However, these individuals are motivated by the sense of belonging they gain from alcohol consumption, indicating that drinking helps them to feel a part of the group and adds a sense of social confidence. This was linked with being more outgoing. This was portrayed by members of this factor who noted its role in social inclusion: "Yeah I suppose drinking does make you feel part of the group because .... so it's just handy sometimes I guess" (participant 17). This was supported by students highlighting that "after having a few drinks you would talk to everybody" (participant 13).

Students in this factor can be described as "peerinfluenced drinkers'. They are influenced by their group of friends, consuming alcohol to gain social confidence on a night out.

\section{Factor 4: inevitable bingers: loss of control causes inevitable negativity}

Students in factor $4(\mathrm{n}=3)$ can be defined as 'inevitable bingers'. The students in this group reported harmful or hazardous drinking based on their AUDIT score. Factor scores describing this group can be seen in table 5 . Inevitable bingers describe how they drink until all the alcohol they have is gone. They recognise that this leaves them in a vulnerable position, foreseeing dangerous situations and forgetting parts of the night. Students noted self-inflicted dangerous situations arising from their own behaviours and drinking habits:

As I was saying I often end up injuring myself. I managed to have three falls in the space of about a half hour ... and I had to go to the doctor twice. (Participant 15)
Compounding this, students worry that they are failing to reach their potential due to their alcohol consumption. One student noted that in order to abstain and remain in control, they must avoid friends and situations: "Whenever the lads are partying I won't go near them or whatever because I know I'll give into peer pressure" ( participant 41).

Interestingly, students in this factor did not identify alcohol consumption as 'fun'; instead, they regard their alcohol consumption as a unique factor which can lead them into dangerous situations. One student noted "I've taught myself to expect massive problems from my alcohol consumption. It's quite a damper in terms of me progressing as a person..." (participant 15). Individuals in this 'inevitable bingers' group described reduced abilities to say no to consuming alcohol but also recognise the harmful effects of abusing this drug. In order to stay in control, they abstain; otherwise, the outcome is inevitable drunkenness.

\section{DISCUSSION}

Alcohol consumption among the university student population is well documented. ${ }^{32-36}$ The WHO recently noted the importance of tailoring health promotion practice to young individuals who are at a time 'of great changes and challenges'. ${ }^{37}$ A narrative synthesis of typology studies highlighted six distinct alcohol consumption profiles among young people. ${ }^{16}$ This study uses Q-methodology to confirm this as four distinct groupings of alcohol consumers among Irish university students generating in-depth, nuanced detail for policymakers. This understanding of university students' drinking pattern is foundational in the public health response to this complex issue.

\section{Policy relevance}

Previous research has focused on the harmful patterns and secondhand effects of hazardous alcohol consumption. ${ }^{33} 35$ Typologies have recently been hypothesised as a pertinent public health tool; however, research in the 
Table 5 Factor 4-inevitable bingers: loss of control causes inevitable negativity

\begin{tabular}{lcc}
\hline Statement & Q-sort value & Z-score \\
\hline I feel that l'm failing to reach my potential due to alcohol consumption. & 3 & $2.32^{*}$ \\
I get myself into dangerous situations following alcohol. & 3 & $1.84^{*}$ \\
Regularly, I do not remember what happens on a night out. & 2 & $1.74^{*}$ \\
I keep on drinking until the alcohol is gone. & 2 & $1.34^{*}$ \\
I abstain from alcohol as I like to remain in control. & 2 & 0.98 \\
I have fun without consuming alcohol. & 1 & 0.68 \\
When I consume alcohol, it occurs in a group. & 1 & 0.67 \\
Socialising involves talking and drinking with my friends. & -1 & 0.58 \\
Socialising involves inviting friends to a party. & -2 & -0.77 \\
The first thing that comes to mind is fun. & -3 & $-0.99^{*}$ \\
I expect no problems from my alcohol consumption. & $-1.74^{*}$ \\
\hline
\end{tabular}

area is in its infancy. The narrative synthesis of predominantly quantitative studies noted six consumption profiles: abstainers, light drinkers, social drinkers, hedonistic drinkers, heavy alcohol consumers and problem alcohol users. ${ }^{16}$ In the current research, students map these to four types. This updated typology combines 'abstainers' and 'light drinkers' to form 'guarded drinkers' and confirmed 'social drinkers' and 'heavy alcohol consumers' as 'peer-influenced consumers'.

Tackling this complex issue requires a multifaceted approach of which the current typology highlights some key issues. These profiles will provide a framework for public policymakers and health promotion practitioners when tackling alcohol consumption at both a microlevel and macrolevel. It would be naive to believe that guarded drinkers may never transition to heavier drinking patterns or suffer harms associated with alcohol consumption. Strategies focusing on social norms marketing, taxation and advertising controls will help ensure that they do not transition to heavier drinking patterns. ${ }^{38} 39$ Peer-influenced drinkers would benefit from social norms marketing to realign their perceived social norms. Previous research has outlined students' inflated perception of peer alcohol consumption and sexual prowess. This campaign, in addition to a ban on sports sponsorship to reduce the impact of advertising, will aid in reducing their consumption level. ${ }^{38-40}$ In contrast, calculated hedonists would benefit most from macrolevel policies including minimum unit pricing and opening hour restrictions. These individuals are motivated to drink by the pleasure domain, and thus methods of tackling their purchasing power will limit their consumption pattern. ${ }^{38-40}$ Inevitable bingers would benefit from minimum unit pricing, a ban on advertising and reduced opening hours and a range of other measures. ${ }^{38}$ In addition to these, robust referral pathways, alcohol addiction counselling and the facilitation of treatment centres are required to support these individuals at a time of great challenge. ${ }^{38} 39$ Finally, these typologies will provide practitioners and health professionals with an insight into student alcohol consumption to aid them in tailoring motivational interventions to students. ${ }^{40}$

\section{Theory}

Recent years have signalled a shift in the discourse surrounding alcohol consumption. ${ }^{41}$ The term 'no risk' has now been supplemented with 'low-risk' signalling public policy acknowledgement of the dangers associated with any level of alcohol consumption. ${ }^{42}$ As recognition of the risk associated with alcohol emerges, so too does an acknowledgement of the heterogeneous nature of consumption. An individual's consumption pattern is linked with pleasure, escape, celebration and their sense of community. ${ }^{43}{ }^{44}$ Szmigin $e t a l^{44}$ recently recognised that "while there is recognition that the term binge drinking is unclear, emotive and politically charged, it continues to be commonly used both in the popular press, government documents and research papers". Peers, community, hedonism, comfort and a lack of control all play a part in an individual's consumption. The current research develops this heterogeneous viewpoint into a typology, confirming previous research while forming a platform for future research, intervention and policy. ${ }^{145-49}$

\section{Strengths and weaknesses}

Q-methodology is a quali-quantilogical approach which combines quantitative and qualitative aspects of research, thus providing a robust method of investigating human subjectivity. ${ }^{23}$ This study uses both previous literature and one-on-one interviews to ensure completeness of discussion on the topic. Statements were selected based on types proposed in a previous systematic review and qualitative study. All statements were discussed and amended among co-authors. Irish university students were sampled from clubs, societies and non-club or society members providing a range of perspectives to the study.

In comparison to a recently published quantitative study investigating the prevalence of alcohol consumption among university students, ${ }^{6}$ AUDIT scores were lower in this Q-methodology study. This may be due to students reporting socially desirable responses when faced with a researcher in a one-on-one interview. ${ }^{50}$ Finally, typologies were not created for male and female students separately, thus impeding further analysis and comparison. 


\section{Public health implications}

The instant gratification which permeates modern society supports an environment suitable for excessive consumption patterns. ${ }^{51}$ Underage drinking and consumption throughout postprimary education is noted across research studies. ${ }^{52} 53$ Drinking to intoxication has become normalised among university students in many western countries. ${ }^{33} 35{ }^{54-56}$ Most recently, research has signalled that excessive consumption occurs in the convergence of time-out and enjoyment. ${ }^{44}$ However, this behaviour impacts society in terms of antisocial behaviour along with adverse health and societal costs. ${ }^{57}$ This is the first study to propose ideal types of alcohol consumption based on the student's own subjectivity. Future research is required to investigate the degree to which each of these ideal types is subscribed. This research provides a framework for policymakers and researchers alike when designing strategies, frameworks, action plans or future research in the area.

\section{Twitter Follow Martin Davoren at @martindavoren}

Contributors MPD was involved in design and conception of study, analysed the data, drafted and edited the manuscript. He is the guarantor. MC was involved in design and conception, drafting and editing of manuscript, qualitative expertise. IJP was involved in design and conception of study, drafting and editing of manuscript. KO was involved in design and conception of study, statistical support, drafting and editing of manuscript, overall supervision of project, Q-methodology expertise. All authors gave full approval of the version to be published.

Funding This research received no specific grant from any funding agency in the public, commercial or not-for-profit sectors.

Competing interests None declared.

Ethics approval The Clinical Research Ethics Committee, University College Cork, Ireland, granted ethical approval for this research.

Provenance and peer review Not commissioned; externally peer reviewed.

Data sharing statement No additional data are available.

Open Access This is an Open Access article distributed in accordance with the Creative Commons Attribution Non Commercial (CC BY-NC 4.0) license, which permits others to distribute, remix, adapt, build upon this work noncommercially, and license their derivative works on different terms, provided the original work is properly cited and the use is non-commercial. See: http:// creativecommons.org/licenses/by-nc/4.0/

\section{REFERENCES}

1. Tosevski DL, Milovancevic MP, Gajic SD. Personality and psychopathology of university students. Curr Opin Psychiatry 2010;23:48.

2. Carey KB, Scott-Sheldon LA, Carey MP, et al. Individual-level interventions to reduce college student drinking: a meta-analytic review. Addict Behav 2007;32:2469-94.

3. Murphy F, Murphy M. The use of social marketing messages to reduce binge drinking among Irish third level female students: Academic Public Administration Studies Archive-APAS. 2010.

4. McCabe SE. Gender differences in collegiate risk factors for heavy episodic drinking. J Stud Alcohol 2002;63:49.

5. Wicki M, Kuntsche E, Gmel G. Drinking at European universities? A review of students' alcohol use. Addict Behav 2010;35:913-24.

6. Davoren MP, Shiely F, Byrne M, et al. Hazardous alcohol consumption among university students in Ireland: a cross-sectional study. BMJ Open 2015;5:e006045

7. Davoren MP, Demant J, Shiely F, et al. Alcohol consumption among university students in Ireland and the United Kingdom from 2002 to 2014: a systematic review. BMC Public Health 2016;16:1-13.
8. Alcohol Working Group. Cardiff and Vale of Glamorgan Alcohol Working Group Action Plan: 2013-2016. 2013.

9. Eurocare: European Alcohol Policy Alliane. Eurocare response to structure for EU Alcohol Action Plan: Belgium. 2014.

10. NUS Alcohol Impact. NUS alcohol impact: about. Secondary NUS Alcohol Impact : About, 2015

11. Purdue University. Student affairs dashboard. Purdue University, 2012.

12. Eriksson Å, Tengström A, Hodgins S. Typologies of alcohol use disorders among men with schizophrenic disorders. Addict Behav 2007;32:1146-63.

13. Cleveland MJ, Mallett KA, White HR, et al. Patterns of alcohol use and related consequences in non-college-attending emerging adults. J Stud Alcohol 2012;74:84.

14. Comasco E, Berglund K, Oreland L, et al. Why do adolescents drink? Motivational patterns related to alcohol consumption and alcohol-related problems. Subst Use Misuse 2010;45:1589-604.

15. Craigs CL, Bewick BM, Gill J, et al. UK student alcohol consumption: a cluster analysis of drinking behaviour typologies. Health Educ J 2012;71:516-26.

16. Davoren MP, Cronin M, Perry IJ, et al. A typology of alcohol consumption among young people-a narrative synthesis. Addict Res Theory 2015:1-13.

17. Thomas DM, Watson RT. Q-sorting and MIS research: a primer. Commun Assoc Inform Syst 2002;8:141-56.

18. Katz DL. Facing the facelessness of public health: what's the public got to do with it? Am J Health Promot 2011;25:361-2.

19. Akhtar-Danesh N, Dehghan M, Morrison KM, et al. Parents' perceptions and attitudes on childhood obesity: a Q-methodology study. J Am Acad Nurse Pract 2011;23:67-75.

20. Davis $\mathrm{CH}$, Michelle $\mathrm{C} . \mathrm{Q}$ methodology in audience research: bridging the qualitative/quantitative 'divide'? Journal of Audience and Reception Studies 2011;8:559-93.

21. Brown SR. A primer on $Q$ methodology. Operant Subjectivity 1993:16:91-138.

22. Van Exel J, de Graaf G. Q methodology: a sneak preview. Online document. 2005. http://wwwqmethodologynet/PDF/Q-methodology

23. Watts S, Stenner P. Doing $Q$ methodological research: theory, method \& interpretation. Sage, 2012.

24. Shabila NP, Al-Tawil NG, Al-Hadithi TS, et al. Using Q-methodology to explore people's health seeking behavior and perception of the quality of primary care services. BMC Public Health 2014;14:2

25. Babor TF, Higgins-Biddle JC, Saunders JB, et al. The alcohol use disorders identification test: guidelines for use in primary care. In Dependence DoMHaS, ed. 2nd edn. Geneva, Switzerland: World Health Organization, 2001:17.

26. Haug S, Ulbricht S, Hanke M, et al. Overestimation of drinking norms and its association with alcohol consumption in apprentices. Alcohol Alcohol 2011;46:204-9.

27. Kelly TM, Donovan JE, Chung T, et al. Brief screens for detecting alcohol use disorder among 18-20-year-old young adults in emergency departments: comparing AUDIT-C, CRAFFT, RAPS4-QF, FAST, RUFT-Cut, and DSM-IV 2-Item Scale. Addict Behav 2009;34:668-74.

28. Barry J, Proops J. Seeking sustainability discourses with $\mathrm{Q}$ methodology. Ecol Econ 1999;28:337-45.

29. Barry J, Proops JLR. Citizenship, sustainability and environmental research: $Q$ methodology and local exchange trading systems. Edward Elgar Pub, 2000.

30. Webler T, Danielson S, Tuler S. Using $Q$ method to reveal social perspectives in environmental research. SERI Rep 2009:09.

31. Elo $S$, Kyngäs $H$. The qualitative content analysis process. $J A d v$ Nurs 2008;62:107-15.

32. Chiauzzi E, Dasmahapatra P, Black RA. Risk behaviors and drug use: a latent class analysis of heavy episodic drinking in first-year college students. Psychol Addict Behav 2013;27: 974-85.

33. Hope A, Dring C, Dring J. College lifestyle and attitudinal national (CLAN) survey. The health of Irish students, health service executive, Health Promotion Unit, Department of Health and Children, Dublin. 2005.

34. Kypri K, Cronin M, Wright CS. Do university students drink more hazardously than their non-student peers? Addiction 2005;100 (5):713-14.

35. Kypri K, Paschall MJ, Langley J, et al. Drinking and alcohol-related harm among New Zealand University students: findings from a national web-based survey. Alcohol Clin Exp Res 2009;33 (2):307-14.

36. McCarthy T. Campus initiatives and student consumption of alcohol at University College Cork 2009-2010: improving student health. University College Cork, 2010. 
37. World Health Organisation. Adolescence: a unique time requiring a tailored response. Secondary Adolescence: a unique time requiring a tailored response. 2013. http://www.euro.who.int/en/health-topics/ disease-prevention/alcohol-use/news/news/2013/02/ adolescence-a-unique-time-requiring-a-tailored-response

38. Anderson P, Chisholm D, Fuhr DC. Effectiveness and cost-effectiveness of policies and programmes to reduce the harm caused by alcohol. Lancet 2009;373:2234-46.

39. Babor TF, Caetano R. Evidence-based alcohol policy in the Americas: strengths, weaknesses, and future challenges. Rev Panam Salud Publica 2005;18:327-37.

40. Winograd RP, Steinley D, Sher K. Searching for Mr. Hyde: a five-factor approach to characterizing "types of drunks". Addict Res Theory 2016;24:1-8.

41. Parker H. Pathology or modernity? Rethinking risk factor analyses of young drug users. Addict Res Theory 2003;11:141-4.

42. Alcohol Action Ireland. Low-risk guidelines. Secondary low-risk guidelines. 2016. http://alcoholireland.ie/alcohol-and-you/guidelines/

43. Measham F. Play space: historical and socio-cultural reflections on drugs, licensed leisure locations, commercialisation and control. Int J Drug Policy 2004;15:337-45.

44. Szmigin I, Griffin C, Mistral W, et al. Reframing "binge drinking" as "calculated hedonism" empirical evidence from the UK. Int J Drug Policy 2008;19:359-66.

45. Demant J, Törrönen J. Changing drinking styles in Denmark and Finland. Fragmentation of male and female drinking among young adults. Subst Use Misuse 2011;46:1244-55.

46. Mathijssen J, Janssen M, van Bon-Martens M, et al. Adolescents and alcohol: an explorative audience segmentation analysis. BMC Public Health 2012;12:742.
47. Reboussin BA, Song EY, Shrestha A, et al. A latent class analysis of underage problem drinking: evidence from a community sample of 16-20-year-olds. Drug Alcohol Depend 2006;83:199.

48. Steinhausen $\mathrm{HC}$, Metzke $\mathrm{CW}$. The validity of adolescent types of alcohol use. J Child Psychol Psychiatry 2003;44:677-86.

49. Stewart C, Power TG. Identifying patterns of adolescent drinking: a tri-ethnic study. J Stud Alcohol 2002;63:156.

50. Morrison V, Bennett P. An introduction to health psychology. Prentice Hall, 2009.

51. Passini S. A binge-consuming culture: the effect of consumerism on social interactions in western societies. Cult Psychol 2013;19: 369-90.

52. Alcohol Action Ireland. Harmful drinking in Ireland is highest among 18-24-year-old age group at $75 \%$ Secondary Harmful drinking in Ireland is highest among 18-24-year-old age group at $75 \% 2015$.

53. Kelly C, Gavin A, Molcho M. et al. The Irish health behaviour in school-aged children (HBSC) study 2010: Department of Health and National University of Ireland, 2012.

54. Agius P, Taft A, Hemphill S, et al. Excessive alcohol use and its association with risky sexual behaviour: a cross-sectional analysis of data from Victorian secondary school students. Aust N Z J Public Health 2013;37:76-82.

55. Alexander EN, Bowen AM. Excessive drinking in college: behavioral outcome, not binge, as a basis for prevention. Addict Behav 2004;29:1199-205.

56. Borsari B, Boyle KE, Hustad JTP, et al. Drinking before drinking pregaming and drinking games in mandated students. Addict Behav 2007;32:2694-705

57. Byrne S. Costs to society of problem alcohol use in Ireland. Dublin: Health Service Executive, 2010. 